\title{
Three-Dimensional Computed Tomography Analysis of Airway Volume Changes Between Open
} and Closed Jaw Positions

Authors: Leslie Glupker ${ }^{1}$, Katherine Kula ${ }^{1}$, Edwin Parks ${ }^{2}$, William Babler ${ }^{2}$, Kelton Stewart ${ }^{1}$ and Ahmed Ghoniema $^{1}$

1: Department of Orthodontics and Oral Facial Genetics, Indiana University School Dentistry, Indianapolis, IN, USA

2: Department of Oral Pathology, Medicine \& Radiology, Indiana University School of Dentistry, Indianapolis, IN, USA

\section{Corresponding author:}

\author{
Ahmed Ghoneima \\ Indiana University School of Dentistry \\ Department of Orthodontics and Oral Facial Genetics
}

1121 West Michigan Street, DS 201

Indianapolis, IN 46202

Phone: $317-278-1653$

Fax: $317-278-1438$

Email: aghoneim@iu.edu

This is the author's manuscript of the article published in final edited form as:

Glupker, L., Kula, K., Parks, E., Babler, W., Stewart, K., \& Ghoneima, A. (2015). Three-dimensional computed tomography analysis of airway volume changes between open and closed jaw positions. American Journal of Orthodontics and Dentofacial Orthopedics, 147(4), 426-434. https://doi.org/10.1016/j.ajodo.2014.11.025 


\section{Three-Dimensional Computed Tomography Analysis of Airway Volume Changes Between}

\section{Open and Closed Jaw Positions}

Abstract:

BACKGROUND: Airway dimensions are closely linked to the bone and soft tissue cranio-facial anatomy. Reduction of the airway is seen with airway disorders and can cause impairments to life. The purpose of this retrospective study was to determine whether changing from open to closed jaw position affects the volume of the nasal cavity, nasopharynx, oropharynx, soft palate, soft tissue thickness of the airway and most constricted area of the airway. MATERIALS AND METHODS: Following reliability studies, this retrospective study analyzed CBCT scans taken in both closed jaw and open jaw positions of 60 subjects who were undergoing diagnosis and treatment of temporomandibular disorder. On each scan, condyle/fossa measures, the volume of airway segments (nasal cavity, nasopharynx, oropharynx), soft palate area, soft tissue thickness of the airway and the most constricted area of the airway and its location were measured using Dolphin ${ }^{\circledR}$ imaging software version 11.5. Differences between the two jaw positions were analyzed using paired t-tests, accepting $\mathrm{p} \leq 0.05$ as significant. RESULTS: Significant changes in airway dimensions were found between closed and open jaw positions. With jaw opening the nasopharynx volume increased, while oropharynx volume decreased. Significant decreases were also found for measurements of Ba-Posterior airway wall, CV2ia-Posterior airway wall, most constricted area, nasal cavity volume, and soft palate area when the jaw was open. CONCLUSIONS: Changing jaw position significantly affects airway dimensions. 


\section{Introduction:}

The upper human airway has two entrances, the nasal cavity and the oral cavity. They combine in the area known as the pharynx. The pharynx consists of three sections: the nasopharynx, oropharynx and laryngopharynx (Figure 1). The nasopharynx is the superior portion of the pharynx that is posterior to the nasal cavity and located behind the soft palate. ${ }^{1}$ The oropharynx, below the nasopharynx, acts as a digestive and respiratory conduit and extends to the epiglottis. The laryngopharynx is that area of the pharynx caudual to the epiglottis.

Narrowing of the airway dimensions can lead to challenges in breathing. For example, the size of pharyngeal and palatine tonsils, in the naso- and oropharynx, respectively, influences airway dimensions. Respiratory diseases associated with edema/inflammation of soft tissue can cause airway restriction and can decrease quality of life. Airway disorders commonly seen include obstructive lung disorders, such as asthma or apneas that show collapse of soft tissue such as obstructive sleep apnea, both showing a decrease in the volume or flow of air. Obstructive sleep apnea (OSA) is defined as having 30 or more episodes of apnea, cessation of airflow for more than 10 seconds, during a normal night of sleep ( 7 hours). ${ }^{2}$ OSA treatment by the orthodontist can vary in invasiveness but all treatments have the aim of allowing continuous breathing without the cessation of airflow experienced by OSA patients. ${ }^{3}$ Previous studies have shown that open mouthed breathing can increase the severity risk of OSA during sleep. ${ }^{4,5}$ During prolonged dental treatment, those with OSA may have an increased risk of detrimental airway changes when their mouths are open.

Evaluation of the airway has become an important aspect in orthodontic treatment planning. The initial orthodontic screening evaluation provides an excellent opportunity to identify symptoms of airway disorders. Questions about snoring, interrupted sleep patterns, and daytime 
somnolence combined with imaging taken at the exam can give indications of possible sleep disorders and support the need for a polysomnograph test for diagnosis. ${ }^{6}$ With or without a diagnosis of OSA it is important to understand the changes that opening the mouth cause in the airways dimensions.

Previous studies on dental patients have shown changes to the airway when patients have their mouths opened with a mouth prop. ${ }^{7,8}$ It is important to understand what the jaw open position does to the patient's airway so that treatment can be adapted to the patient's needs. Some patients may need more breaks during treatment to keep their oxygen saturation higher. Even though the CPAP is the "gold standard" in treatment, there are other treatment modalities that can be used such as the use of dental appliances to improve airway function or advancing the upper or lower jaw by orthognathic surgery. Most dental appliances aim to move the mandibular jaw forward and open the airway. Studies have shown airway changes with both the mandibular advancement splint and tongue stabilizing device. ${ }^{9}$ We know that positioning the jaw forward improves the airway, but in treating OSA patient's with dental appliances is opening the jaw beneficial or detrimental? It has been reported that head and jaw positions would significantly affect the airway dimensions. ${ }^{8}$ However, comparing open jaw position to closed jaw position and its influence on the airway dimensions using 3D CBCT imaging has not been previously studied.

A few studies have previously evaluated the differences in airway between open and closed jaw position. However, these were done in patients wearing rubber dams or using mouth props for restorative dental procedures. ${ }^{7,8}$ The study by Iwatani et al had 20 adult subjects who were imaged with MRI. ${ }^{8}$ They found that the oropharyngeal airway volume decreased significantly with the mouth open but the retropalatal and hypopharyngeal areas were not significantly 
affected. ${ }^{8}$ The second study by Ito et al was done on 13 subjects and using lateral cephalograms, except for one subject where a computed tomograph was taken. ${ }^{7}$ They reported a decrease in upper airway sagittal diameter when using a mouth prop. Subjects also indicated increased dyspnea when their mouth was maximally open. ${ }^{7}$ With the greater interest in airway disorders and the estimated $80-90 \%$ of people with undiagnosed OSA having moderate-severe OSA, it is important to understand the changes that occur when a patient fully opens their jaw.

Imaging methods to view the airway include cephalometric radiographs, $\mathrm{CBCT}$, and Magnetic Resonance Imaging (MRI). Lateral cephalometric radiographs were the only available method before CBCT and MRIs. This method had the limitation of imaging a 3-dimensional structure in 2D. Volume and cross-sectional area were not able to be accurately assessed with lateral cephalometric radiographs. ${ }^{10}$ Some additional limitations with lateral cephalometric radiographs are image magnification/enlargement and distortion, structure overlap, limited identifiable landmarks, and positioning problems. ${ }^{11}$ MRI was used to measure the airway 3-dimensionally and to visualize ventilation differences in respiratory diseases. ${ }^{12}$ Studies have shown that both CBCT and MRI imaging methods are accurate ways to measure the airway. ${ }^{13-15}$ However CBCT offers an easier, quicker, and more accurate method to obtain a view of a patient's airway than MRI. ${ }^{16}$ CBCT has been used for measuring airway in studies looking into changes related to facial bony structure, developmental changes, before and after varying orthodontic treatments, maxillofacial surgeries, treatment of TMD and cleft lip/palate patients. CBCT imaging is an accurate way of visualizing the condyle and measuring condyle position and location. ${ }^{17,18}$

This retrospective radiographic study is an exploratory study to determine the effects of mandibular positional changes on the upper airway dimensions. 


\section{Materials/Methods:}

Population and selection criteria:

Following university IRB approval, this retrospective study included 60 patients' CBCT images retrieved from the archive of the Indiana University School of Dentistry’s (IUSD) Oral Pathology, Medicine and Radiology Department. Each subject had two 13.3 inch scans taken: one in closed jaw position and one at maximum open position (some showing a limited field of

view due to jaw opening). Inclusion criteria for this study: 1. Patient age greater or equal to 18 years, 2. No previous orthognathic surgery, 3. Two CBCT images (closed/open) taken at same session, 4. No airway pathology noted on radiology Cone Beam Report. The average age of the subjects was 40 years, 4 months \pm 17 years, 8 months. All subjects were female.

Data collection and measurements:

CBCT images were downloaded into Dolphin ${ }^{\circledR}$ 3D imaging software version 11.5 (Patterson Dental Supply, Inc., Chatsworth, CA) and measured on the same computer and monitor. All 60 patient's CBCT's were coded and information on age and gender recorded. Then subject information was de-identified.

Because of the limited field of view (FOV), some of the 3D-CBCT images did not show both maxillary and mandibular incisors. Because of this, the condyle/fossa relationship of the jaw was used to determine the amount of opening by the amount of translation of the condylar head along the articular eminence instead of measuring the vertical distances between the central incisors of the maxilla and mandible. On views that show both condyle and incisors, the vertical distance between the maxillary and mandibular incisors was also measured. Both the rotation and translational movement along the articular eminence to the apex of the eminence lead to 
opening of the mouth. ${ }^{19}$ The magnitude of opening is based on the amount of rotation and the amount of translation during mandibular movement. ${ }^{20}$ Both translation and rotation were measured on both condyles in both open and closed radiographs. Translation was determined by visually dividing the glenoid fossa into 6 sections: center of the fossa, $1 / 4,1 / 2,3 / 4$, top of eminence, and past eminence (Figure 2) and determining how far along the glenoid fossa the condyle has translated. ${ }^{21}$ This view was obtained from a sagittal slice through the middle of both condylar heads. Rotation was measured by taking five linear measurements from the glenoid fossa to condyle. A sagittal slice through the middle of the condyles was obtained. Then a horizontal plane was placed through the widest width of the condylar heads visible on the slice. Lines were then drawn through mid-point of condylar head crossing at $45^{\circ}, 90^{\circ}$ and $135^{\circ}$. Five linear measurements representing anterior, antero-superior, superior, postero-superior, and posterior directions were taken from the fossa wall to the center of condyle (the intersection of the 5 lines) (Figure 3). All images were oriented in the sagittal, axial and coronal planes before taking measurements following methods used in previous airway studies. ${ }^{22}$ This allowed us to determine changes in the condylar head position as the jaw opens.

The airway and soft tissue measurements taken on CBCTs in both open and closed jaws are presented in Table I and Figures 4-7:22-24

Sample size:

Based on a prior study and assuming a correlation of 0.9 between the closed and open measurements, the standard deviations of the differences between the closed and open measurements were estimated to be $950 \mathrm{~mm}^{3}$ for nasopharynx volume, $3400 \mathrm{~mm}^{3}$ for oropharynx volume, $4000 \mathrm{~mm}^{3}$ for total airway volume, and $50 \mathrm{~mm}^{3}$ for most constricted area of 
the airway. ${ }^{22}$ With a sample size of 60 subjects, the study was designed to have $80 \%$ power to detect differences between the closed and open image measurements of $350 \mathrm{~mm}^{3}$ for nasopharynx volume, $1250 \mathrm{~mm}^{3}$ for oropharynx volume, $1470 \mathrm{~mm}^{3}$ for total airway volume, and $19 \mathrm{~mm}^{3}$ for most constricted airway.

Reliability Testing:

The primary investigator, L.G., performed reliability measures using 10 coded and randomized CBCT's on all parameters. These CBCT's were coded and randomized by the investigator's mentor (A.G.). Thus, the investigator was blinded to the names of the subjects. In two weeks, the same ten cases were re-traced in a new randomly assigned order determined by A.G. The reliability was calculated with a goal that the intraclass correlation coefficient (ICC) $\geq$ 0.80. This process was repeated until ICCs were $\geq 0.80$.

Statistical Analysis:

The reliability data was analyzed using intraclass correlation coefficients (ICCs) and Bland-Altman plots to assess the intra-examiner reliability. Summary statistics (mean, standard deviation, standard error, range) were calculated for all measurements from both the closed and open jaw positions. The differences between the measurements and the ratio of the measurements for the two jaw positions were calculated and summarized. Comparisons between the closed and open jaw position measurements were made using paired t-tests accepting $\mathrm{p} \leq 0.05$ as significant. For measurements that were made on both the left and right sides, mixed-model ANOVAs were used to evaluate whether the closed vs. open comparison was affected by side. Pearson correlation coefficients were used to evaluate the associations among the airway 
parameters. Translation of the condyles was compared using Cochran-Mantel-Haenszel tests for repeated ordered categorical data.

Results:

A correlation coefficient of $>.80$ was obtained for all reliability values except the anterosuperior condyle measurement which had too much variability to accept the readings.

Descriptive statistics for the measurements in the closed and open jaw positions and for the differences (open-closed) are presented in Tables II and III. Statistically significant differences were detected in multiple parameters between the groups (Table III). Measurements that decreased in the open position compared to the closed position were basion - posterior airway wall, CV2ia - posterior airway wall, most constricted area, nasal cavity volume, oropharynx volume, and soft palate area, while nasopharynx volume and U1 tip - L1 tip increased (Table III). The values of AA-posterior airway wall and soft palate length did not show any significant differences. Statistics for each condyle measurement by side and jaw position are summarized (Table IV). A summary of the condyle measurement statistics for the difference between the closed and open jaw positions of each condyle measure is listed in Table V. Comparisons of condyle positions shows the differences between the open and closed jaw positions with the open position always significantly larger than closed (Table VI). This shows there was a change in jaw position with the jaw open but no difference between right and left sides.

Correlation coefficients were calculated to evaluate the associations of the airway parameters to the U1 tip-L1 tip and the position of the condyle. The U1 tip-L1 tip had strong positive correlations with the posterior right and left condyle positions ( $\mathrm{r}=0.81$ and 0.82 , respectively); all other correlations with airway parameters were negligible (correlations between -0.20 and 
$+0.25)$. Antero-superior left condyle position had weak negative correlation $(\mathrm{r}=-0.32)$ with AAposterior airway wall and antero-superior right condyle position had weak negative correlation $(\mathrm{r}=-0.39)$ with soft palate length. All other correlations of the antero-superior, posterior, posterosuperior, and superior left and right condyle positions with the airway parameters were negligible, between -0.27 and +0.29 (Table VII).

\section{Discussion:}

In the present study, we used CBCTs to look 3-dimensionally at the oropharynx changes between closed and open jaw position. We also looked into changes to the nasopharynx, nasal cavity and soft tissue changes for a more thorough investigation into changes that occur with opening the jaw. Several studies have now used CBCTs to view and measure the airway volume. ${ }^{10,16,25}$ It has been found to be a reliable source for assessing airway dimensions. The Dolphin ${ }^{\circledR}$ 3D imaging software version 11.5 has been shown to be accurate and it has been used in numerous previous studies. ${ }^{10}$ A limitation with the study was that CBCTs were completed on subjects that were undergoing TMD diagnosis and treatment. It is possible TMD symptoms may cause the path of opening to differ from patients with no TMD symptoms; however, our data did not show significant differences between right and left condyle movements. In our study, there were not significant differences between the condyle movements between right and left sides.

The results demonstrated that opening the jaw causes significant increases in several parts of the upper airway, whereas others decrease significantly. The oropharynx showed a statistically significant decrease in volume matching the previous studies done by Iwatani and Ito. ${ }^{7,8}$ Our study also showed a statistically significant increase in the nasopharynx volume. The area of most constriction showed a significant decrease and tended to move into the oropharynx 
with opening of the jaw (Table VIII). Forty-nine of the subjects (82\%) had the area of most constriction in the oropharynx with the jaw open. $55 \%$ of subjects' area of most constriction stayed in the same portion of the airway. The only values not showing a significant change between closed and open were AA-posterior airway wall and soft palate length. All other values had a significant difference between open and closed jaw positions.

Out of all the measurements showing a significant difference between the two jaw positions, only nasopharynx volume and U1 tip-L1 tip showed an increase in size with mouth opening. The other values showed an inverse relationship and became smaller when going from closed to open jaw. This can be explained by the fact that as the patient opens his jaw, the upper and lower incisor become farther apart and with opening the soft palate drops down and shows an increase in length. With opening the tongue tends to drop posteriorly. This would drop the tongue into the oropharynx/hypopharynx causing a decrease in oropharynx volume. The nasopharynx volume could become larger with the lengthening of the soft palate. There was decrease in soft tissue size for measures Basion to the posterior airway wall and CV2ia to the posterior airway wall. This would lead to an increase in nasopharynx volume which was also shown.

Condyle position was used to detect if there was a change in jaw position. In each value antero-superior, posterior, postero-superior, superior there was a significant change between closed and open jaw positions. There was no significant difference between right and left side values. The anterior condyle value was only obtained for one scan because of the articular eminence shape. For the posterior, postero-superior, superior, and antero-superior values, all became larger with opening. This may be possible as the condyle translates and rotates downward and forward with opening. The condyles were also shown to move forward and 
downward along the eminence with opening through the visual measure. With the jaw closed, the majority of condyles were in the center of fossa position. After opening, the majority were at $3 / 4$ down the eminence. These changes show that the patients had a difference in jaw position between with the mouth open. This means any airway changes shown are because of the change in jaw position.

This study has shown that there are significant differences between open and closed jaw positions. Further studies will be needed to determine if it is only valid at maximum opening or if the oropharynx progressively decreases as the mouth opens. Further studies on oral devices would be needed to determine the effect of vertical changes. If the same even occurs when patients are supine and open their mouth for dental treatment, then dental treatment may be negatively impacting the airway and in some patients' treatment timing or positioning of the jaw may need to be changed to accommodate the airway.

Conclusion:

There is a significant change in airway dimensions between open and closed jaw positions. The nasopharynx volume increased with opening while the upper airway soft tissue thickness, nasal cavity volume, oropharynx volume, most constricted area and soft palate area decreased. The area of most constriction also appeared to move to the location of the oropharynx with opening of the jaw or remain in its original position at the oropharynx. 
1. Martini FT, M; Tallitsch, R. Human Anatomy. Francisco, CA: Pearson Education Inc.; 2006.

2. Meyer JB, Jr., Knudson RC. The sleep apnea syndrome. Part I: Diagnosis. J Prosthet Dent 1989;62:675679.

3. Usmani ZA, Chai-Coetzer CL, Antic NA, McEvoy RD. Obstructive sleep apnoea in adults. Postgrad Med J 2013;89:148-156.

4. Kim EJ, Choi JH, Kim KW, Kim TH, Lee SH, Lee HM et al. The impacts of open-mouth breathing on upper airway space in obstructive sleep apnea: 3-D MDCT analysis. Eur Arch Otorhinolaryngol 2011;268:533-539.

5. Lee SH, Choi JH, Shin C, Lee HM, Kwon SY, Lee SH. How does open-mouth breathing influence upper airway anatomy? Laryngoscope 2007;117:1102-1106.

6. Patel D, Ash S, Evans J. The role of orthodontics and oral and maxillofacial surgery in the management of obstructive sleep apnoea - a single case report. Br Dent J 2004;196:264-267.

7. Ito $\mathrm{H}$, Kawaai $\mathrm{H}$, Yamazaki S, Suzuki Y. Maximum opening of the mouth by mouth prop during dental procedures increases the risk of upper airway constriction. Ther Clin Risk Manag 2010;6:239-248.

8. Iwatani K, Matsuo K, Kawase S, Wakimoto N, Taguchi A, Ogasawara T. Effects of open mouth and rubber dam on upper airway patency and breathing. Clin Oral Investig 2013;17:1295-1299.

9. Sutherland K, Deane SA, Chan AS, Schwab RJ, Ng AT, Darendeliler MA et al. Comparative effects of two oral appliances on upper airway structure in obstructive sleep apnea. Sleep 2011;34:469-477. 10. Weissheimer A, Menezes LMd, Sameshima GT, Enciso R, Pham J, Grauer D. Imaging software accuracy for 3-dimensional analysis of the upper airway. Am J Orthod Dentofacial Orthop 2012;142:801813.

11. Cheung T, Oberoi S. Three dimensional assessment of the pharyngeal airway in individuals with nonsyndromic cleft lip and palate. PLoS One 2012;7:e43405.

12. Kirby M, Svenningsen S, Kanhere N, Owrangi A, Wheatley A, Coxson HO et al. Pulmonary Ventilation Visualized using Hyperpolarized Helium-3 and Xenon-129 Magnetic Resonance Imaging: Differences in COPD and Relationship to Emphysema. J Appl Physiol 2012.

13. Tai K, Park JH, Hayashi K, Yanagi Y, Asaumi JI, lida S et al. Preliminary study evaluating the accuracy of MRI images on CBCT images in the field of orthodontics. J Clin Pediatr Dent 2011;36:211-218.

14. Schwab RJ, Pasirstein M, Pierson R, Mackley A, Hachadoorian R, Arens R et al. Identification of upper airway anatomic risk factors for obstructive sleep apnea with volumetric magnetic resonance imaging.

Am J Respir Crit Care Med 2003;168:522-530.

15. Ghoneima A, Kula K. Accuracy and reliability of cone-beam computed tomography for airway volume analysis. Eur J Orthod 2013;35:256-261.

16. Ogawa T, Enciso R, Shintaku WH, Clark GT. Evaluation of cross-section airway configuration of obstructive sleep apnea. Oral Surgery, Oral Medicine, Oral Pathology, Oral Radiology, and Endodontology 2007;103:102-108.

17. Ilguy D, Ilguy M, Fisekcioglu E, Dolekoglu S, Ersan N. Articular eminence inclination, height, and condyle morphology on cone beam computed tomography. ScientificWorldJournal 2014;2014:761714. 18. Arieta-Miranda JM, Silva-Valencia M, Flores-Mir C, Paredes-Sampen NA, Arriola-Guillen LE. Spatial analysis of condyle position according to sagittal skeletal relationship, assessed by cone beam computed tomography. Prog Orthod 2013;14:36.

19. Mapelli A, Galante D, Lovecchio N, Sforza C, Ferrario VF. Translation and rotation movements of the mandible during mouth opening and closing. Clin Anat 2009;22:311-318.

20. Lemoine JJ, Xia JJ, Gateno J, Liebschner MA. Radiographic analysis for jaw motion normalization. J Oral Maxillofac Surg 2005;63:961-967.

21. Kim S-G, Kim D-S, Choi S-C, Lee S-S, Heo M-S, Huh K-H et al. The relationship between threedimensional principal rotations and mandibular deviation. Oral Surgery, Oral Medicine, Oral Pathology, Oral Radiology, and Endodontology 2010;110:e52-e60. 
22. Smith T, Ghoneima A, Stewart K, Liu S, Eckert G, Halum S et al. Three-dimensional computed tomography analysis of airway volume changes after rapid maxillary expansion. Am J Orthod Dentofacial Orthop 2012;141:618-626.

23. Sears CR, Miller AJ, Chang MK, Huang JC, Lee JS. Comparison of pharyngeal airway changes on plain radiography and cone-beam computed tomography after orthognathic surgery. J Oral Maxillofac Surg 2011;69:e385-394.

24. Park SB, Kim YI, Son WS, Hwang DS, Cho BH. Cone-beam computed tomography evaluation of shortand long-term airway change and stability after orthognathic surgery in patients with Class III skeletal deformities: bimaxillary surgery and mandibular setback surgery. Int J Oral Maxillofac Surg 2012;41:8793.

25. Grauer D, Cevidanes LS, Styner MA, Ackerman JL, Proffit WR. Pharyngeal airway volume and shape from cone-beam computed tomography: relationship to facial morphology. Am J Orthod Dentofacial Orthop 2009;136:805-814. 
Figure Legends

Figure 1: Airway anatomy

Figure 2: Condyle translation measured as distance traveled toward eminence.

Figure 3: Linear condyle measurements closed jaw: anterior, antero-superior, superior, posterosuperior, and posterior.

Figure 4: Measurements closed jaw: airway measurements in green (A: nasal cavity; B: nasopharynx; C: oropharynx). Area measurement in red (D: Soft palate). Linear measurements in blue (E: soft palate; F: Ba-posterior airway wall; G: AA-posterior airway wall; H: CV2-posterior airway wall).

Figure 5: Measurements open jaw: airway measurements in green (A: nasal cavity; B: nasopharynx; C: oropharynx). Area measurement in red (D: Soft palate). Linear measurements in blue (E: soft palate; F: Ba-posterior airway wall; G: AA-posterior airway wall; H: CV2-posterior airway wall).

Figure 6: Nasal cavity coronal boundary

Figure 7: 3-dimensional airway boundaries rendering. A: Sagittal view of a. nasal cavity, b. nasopharynx, c. oropharynx. B: Frontal view of a. nasal cavity, b. nasopharynx, c. oropharynx. 
Tables

Table I: Definitions of anatomic areas

Table II: Summary Statistics for Each Measurement for open and closed jaw positions

Table III: Summary Statistics for Differences between open and closed jaw positions

Table IV: Summary statistics for each condyle measurement by side for open and closed jaw positions

Table IV: Summary Statistics for Condyle Measurements Differences between open and closed jaw positions

Table VI: Comparison of Condyle Positions

Table VII: Correlations of airway parameters with condyle positions

Table VIII: Area of most constriction 
Table I: Definitions of anatomic areas

\begin{tabular}{|c|c|c|c|c|}
\hline & Anterior boundary & $\begin{array}{l}\text { Posterior } \\
\text { boundary }\end{array}$ & $\begin{array}{l}\text { Superior } \\
\text { boundary }\end{array}$ & $\begin{array}{l}\text { Inferior } \\
\text { boundary }\end{array}$ \\
\hline Nasal cavity & $\begin{array}{l}\text { line connecting the } \\
\text { anterior nasal spine } \\
\text { (ANS) - the apex of } \\
\text { the nasal bone - } \\
\left(\mathrm{N}_{\mathrm{a}}\right)\end{array}$ & $\begin{array}{l}\text { line extending } \\
\text { from Sella point } \\
\text { (S) - Posterior } \\
\text { nasal spine } \\
\text { (PNS) }\end{array}$ & $\begin{array}{l}\text { line connecting } \\
\text { Nasion or the } \\
\text { highest point on } \\
\text { nasal bone } 1 \mathrm{~mm} \\
\text { inferior to edge of } \\
\text { field of view }\left(\mathrm{N}_{\mathrm{m}}\right) \\
\text { - Sella point }(\mathrm{S})\end{array}$ & $\begin{array}{l}\text { line extending } \\
\text { from the anterior } \\
\text { nasal spine } \\
\text { (ANS) - } \\
\text { Posterior nasal } \\
\text { spine (PNS) }\end{array}$ \\
\hline \multicolumn{5}{|c|}{$\begin{array}{l}\text { Nasal cavity coronal boundary: outline of nasal cavity in section containing maxillary first molar } \\
\text { bifurcation, starting at crista galli and running down to the nasal floor following sidewalls of right and } \\
\text { left nasal cavity }\end{array}$} \\
\hline Nasopharynx & $\begin{array}{l}\text { line extending from } \\
\text { Sella point }(\mathrm{S})- \\
\text { Posterior nasal spine } \\
\text { (PNS) }\end{array}$ & $\begin{array}{l}\text { line extending } \\
\text { from Sella point } \\
\text { (S) - tip of the } \\
\text { odontoid process }\end{array}$ & & $\begin{array}{l}\text { line extending } \\
\text { from posterior } \\
\text { nasal spine } \\
\text { (PNS) - tip of } \\
\text { the odontoid } \\
\text { process }\end{array}$ \\
\hline Oropharynx & $\begin{array}{l}\text { the line extending } \\
\text { from posterior nasal } \\
\text { spine (PNS) - } \\
\text { perpendicular } \\
\text { dropping to line } \\
\text { parallel to ruler } \\
\text { running through } \\
\text { anterior-inferior } \\
\text { border of } \mathrm{C} 2\end{array}$ & $\begin{array}{l}\text { line extending } \\
\text { from the tip of } \\
\text { the odontoid } \\
\text { process - } \\
\text { anterior-inferior } \\
\text { border of C2 }\end{array}$ & $\begin{array}{l}\text { line extending } \\
\text { from posterior } \\
\text { nasal spine (PNS) } \\
\text { - tip of the } \\
\text { odontoid process }\end{array}$ & $\begin{array}{l}\text { line extending } \\
\text { from posterior } \\
\text { nasal spine } \\
\text { (PNS) - tip of } \\
\text { the odontoid } \\
\text { process }\end{array}$ \\
\hline \multicolumn{5}{|l|}{ Soft-palate } \\
\hline \multicolumn{5}{|c|}{ Length: Length from PNS to the most posterior-inferior point of soft palate } \\
\hline \multicolumn{5}{|c|}{ Area: Confined by the area that starts and ends at PNS through the uvula tip } \\
\hline \multicolumn{5}{|c|}{\begin{tabular}{l|l|l} 
Soft Tissue Measurements & & \\
\end{tabular}} \\
\hline \multicolumn{5}{|c|}{\begin{tabular}{|l|l|l|} 
AA point to the posterior airway wall & & \\
\end{tabular}} \\
\hline \multicolumn{5}{|c|}{$\mathrm{CV} 2_{\text {ia }}$ most inferior-anterior point of CV2 to the posterior airway wall } \\
\hline \multicolumn{3}{|c|}{ Basion to the posterior airway wall } & & \\
\hline Most constric & 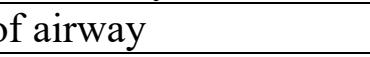 & & & \\
\hline
\end{tabular}


Table II. Summary statistics for each measurement for open and closed jaw positions.

\begin{tabular}{|l|l|l|c|c|c|c|}
\hline \multicolumn{1}{|c|}{ Measurement } & Open/Closed & $\mathrm{N}$ & Mean & SD & Minimum & Maximum \\
\hline AA-posterior airway wall (mm) & Closed & 60 & 3.37 & 1.57 & 0.10 & 8.40 \\
\hline & Open & 60 & 3.32 & 1.53 & 1.30 & 8.00 \\
\hline Basion - posterior airway wall (mm) & Closed & 60 & 16.95 & 3.65 & 11.60 & 29.50 \\
\hline & Open & 60 & 16.61 & 3.59 & 11.20 & 30.20 \\
\hline CV2ia - posterior airway wall (mm) & Closed & 60 & 3.94 & 0.89 & 2.70 & 8.50 \\
\hline & Open & 60 & 3.68 & 1.10 & 1.30 & 8.00 \\
\hline Most constricted area (mm2) & Closed & 60 & 177.11 & 79.49 & 19.90 & 323.60 \\
\hline & Open & 60 & 112.05 & 59.48 & 29.80 & 272.80 \\
\hline Nasal Cavity Volume (mm3) & Closed & 60 & 16590 & 4351 & 9440 & 30230 \\
\hline & Open & 60 & 15487 & 4182 & 6714 & 26552 \\
\hline Nasopharynx Volume (mm3) & Closed & 60 & 7015 & 1951 & 1926 & 10873 \\
\hline & Open & 60 & 7556 & 2007 & 1991 & 11230 \\
\hline Oropharynx Volume (mm3) & Closed & 60 & 11893 & 4060 & 3209 & 20110 \\
\hline & Open & 60 & 9893 & 3499 & 3921 & 17924 \\
\hline Soft palate area (mm2) & Closed & 60 & 286.94 & 49.24 & 185.00 & 400.10 \\
\hline & Open & 60 & 272.09 & 50.24 & 120.50 & 385.10 \\
\hline Soft palate length (mm) & Closed & 60 & 37.88 & 4.35 & 28.40 & 47.90 \\
\hline & Open & 60 & 38.68 & 4.15 & 25.50 & 45.00 \\
\hline U1 tip - L1 tip (mm) & Closed & 60 & -2.84 & 1.99 & -7.20 & 5.20 \\
\hline & Open & 57 & 20.76 & 8.13 & 5.20 & 36.80 \\
\hline
\end{tabular}

Table III. Summary statistics for the difference between open and closed jaw positions.

\begin{tabular}{|l|c|c|c|c|c|c|}
\hline \multicolumn{1}{|c|}{ Measurement } & & & & $\begin{array}{c}\text { Mean } \\
\text { difference }\end{array}$ & & \\
& $\mathrm{N}$ & Minimum & Maximum & open-closed & SD & P value \\
\hline AA-posterior airway wall (mm) & 60 & -1.60 & 3.40 & -0.05 & 0.88 & 0.6597 \\
\hline Basion - posterior airway wall (mm) & 60 & -3.60 & 3.40 & -0.34 & 1.11 & 0.0217 \\
\hline CV2ia - posterior airway wall (mm) & 60 & -2.30 & 1.50 & -0.26 & 0.82 & 0.0173 \\
\hline Most constricted area (mm2) & 60 & -217.0 & 104.10 & -65.06 & 68.78 & $<.0001$ \\
\hline Nasal Cavity Volume (mm3) & 60 & -5900 & 7010 & -1103 & 2028 & $<.0001$ \\
\hline Nasopharynx Volume (mm3) & 60 & -2700 & 2457 & 542 & 930 & $<.0001$ \\
\hline Oropharynx Volume (mm3) & 60 & -10096 & 5322 & -2000 & 3005 & $<.0001$ \\
\hline Soft palate area (mm2) & 60 & -190.7 & 75.20 & -14.85 & 43.93 & 0.0112 \\
\hline Soft palate length (mm) & 60 & -22.40 & 10.40 & 0.80 & 4.30 & 0.1536 \\
\hline U1 tip - L1 tip (mm) & 57 & 10.10 & 39.20 & 23.59 & 8.15 & $<.0001$ \\
\hline
\end{tabular}

$\mathrm{P}$ value is significant at $\mathrm{P} \leq .05$ 
Table IV. Summary statistics for each condyle measurement by side for open and closed jaw positions.

\begin{tabular}{|l|l|l|c|c|c|c|c|}
\hline Measurement & Side & Open/Closed & N & Mean & SD & Minimum & Maximum \\
\hline Anterior (mm) & left & Closed & 39 & 7.78 & 1.54 & 5.10 & 12.00 \\
\hline & & Open & 1 & 9.00 &. & 9.00 & 9.00 \\
\hline & right & Closed & 40 & 8.05 & 1.92 & 4.80 & 13.20 \\
\hline & & Open & 1 & 11.40 &. & 11.40 & 11.40 \\
\hline Antero-superior (mm) & left & Closed & 60 & 5.55 & 1.10 & 3.60 & 8.70 \\
\hline & & Open & 34 & 6.20 & 1.65 & 2.20 & 12.30 \\
\hline & right & Closed & 60 & 5.67 & 1.15 & 3.70 & 9.20 \\
\hline & & Open & 37 & 6.16 & 1.67 & 4.00 & 13.40 \\
\hline Posterior (mm) & left & Closed & 60 & 7.24 & 1.66 & 3.90 & 11.10 \\
\hline & & Open & 60 & 16.91 & 5.88 & 5.20 & 34.70 \\
\hline & right & Closed & 60 & 7.29 & 1.75 & 4.00 & 12.90 \\
\hline & & Open & 60 & 16.46 & 5.19 & 6.20 & 27.20 \\
\hline Postero-superior (mm) & left & Closed & 60 & 5.59 & 1.21 & 3.30 & 8.80 \\
\hline & & Open & 60 & 11.55 & 4.04 & 4.40 & 19.10 \\
\hline & right & Closed & 60 & 5.74 & 1.63 & 2.80 & 12.30 \\
\hline & & Open & 60 & 11.80 & 4.31 & 4.60 & 25.50 \\
\hline Superior (mm) & left & Closed & 60 & 5.72 & 1.12 & 3.50 & 8.80 \\
\hline & & Open & 56 & 7.11 & 2.81 & 2.20 & 17.10 \\
\hline & right & Closed & 60 & 5.84 & 1.36 & 3.30 & 10.30 \\
\hline & & Open & 57 & 7.13 & 2.73 & 4.10 & 19.30 \\
\hline
\end{tabular}

Table V. Summary statistics for the difference between open and closed jaw positions for each condyle measurement by side.

\begin{tabular}{|lll|l|c|c|c|c|}
\hline \multicolumn{1}{|c|}{ Measurement } & Side & $\mathrm{N}$ & \multicolumn{1}{c|}{ Minimum } & Maximum & $\begin{array}{c}\text { Mean } \\
\text { difference } \\
\text { open-closed }\end{array}$ & SD \\
\hline Anterior (mm) & left & 1 & 0.00 & 0.00 & 0.00 &. \\
\hline & right & 1 & -0.20 & -0.20 & -0.20 &. \\
\hline Antero-superior (mm) & left & 34 & -2.50 & 6.70 & 0.77 & 1.69 \\
\hline & right & 37 & -2.80 & 6.30 & 0.44 & 1.62 \\
\hline Posterior (mm) & left & 60 & -0.30 & 23.60 & 9.67 & 5.48 \\
\hline & right & 60 & 0.10 & 20.60 & 9.17 & 4.64 \\
\hline Postero-superior (mm) & left & 60 & -0.70 & 13.30 & 5.96 & 3.92 \\
\hline & right & 60 & -1.60 & 13.40 & 6.06 & 4.04 \\
\hline Superior (mm) & left & 56 & -3.90 & 9.90 & 1.40 & 2.82 \\
\hline & right & 57 & -2.70 & 11.80 & 1.27 & 2.46 \\
\hline
\end{tabular}

Table VI. Comparison of condyle positions.

\begin{tabular}{|l|c|c|c|}
\hline \multicolumn{1}{|c|}{ Measurement } & Comparison & Difference & P value \\
\hline Antero-superior $(\mathrm{mm})$ & left \& right n.s. & -0.12 & 0.2815 \\
\hline & Open $>$ Closed & 0.55 & 0.0094 \\
\hline Posterior $(\mathrm{mm})$ & left \& right n.s. & 0.07 & 0.7270 \\
\hline & Open $>$ Closed & 9.04 & $<.0001$ \\
\hline Postero-superior $(\mathrm{mm})$ & left \& right n.s. & -0.15 & 0.3796 \\
\hline & Open $>$ Closed & 6.00 & $<.0001$ \\
\hline Superior $(\mathrm{mm})$ & left \& right n.s. & -0.08 & 0.5671 \\
\hline & Open $>$ Closed & 1.35 & $<.0001$ \\
\hline
\end{tabular}

$P$ value is significant at $P \leq .05$ 
Table VII. Correlations of airway parameters with condyle positions.

\begin{tabular}{|l|c|c|c|c|c|c|c|c|c|}
\hline & $\begin{array}{c}\text { U1 tip - } \\
\text { L1 tip } \\
(\mathrm{mm})\end{array}$ & $\begin{array}{c}\text { Antero- } \\
\text { superior } \\
(\mathrm{mm}) \text { left }\end{array}$ & $\begin{array}{c}\text { Posterior } \\
(\mathrm{mm}) \text { left }\end{array}$ & $\begin{array}{c}\text { Postero- } \\
\text { superior } \\
(\mathrm{mm}) \text { left }\end{array}$ & $\begin{array}{c}\text { Superior } \\
(\mathrm{mm}) \text { left }\end{array}$ & $\begin{array}{c}\text { Antero- } \\
\text { superior } \\
(\mathrm{mm}) \text { right }\end{array}$ & $\begin{array}{c}\text { Posterior } \\
(\mathrm{mm}) \text { right }\end{array}$ & $\begin{array}{c}\text { Postero- } \\
\text { superior } \\
\text { Mmasurement }\end{array}$ & $\begin{array}{c}\text { Superior } \\
\text { (mm) } \\
\text { right }\end{array}$ \\
\hline $\begin{array}{l}\text { U1 tip - L1 tip } \\
\text { (mm) }\end{array}$ & 1.00 & -0.07 & 0.81 & 0.12 & 0.09 & 0.09 & 0.82 & 0.24 & -0.02 \\
\hline $\begin{array}{l}\text { AA-posterior } \\
\text { airway wall } \\
\text { (mm) }\end{array}$ & -0.20 & -0.32 & -0.14 & 0.16 & 0.09 & -0.07 & -0.22 & -0.02 & 0.09 \\
\hline $\begin{array}{l}\text { Basion - } \\
\text { posterior airway } \\
\text { wall (mm) }\end{array}$ & -0.19 & -0.15 & -0.05 & 0.10 & -0.01 & -0.09 & -0.07 & 0.09 & -0.17 \\
\hline $\begin{array}{l}\text { CV2ia - posterior } \\
\text { airway wall } \\
\text { (mm) }\end{array}$ & 0.15 & -0.06 & 0.26 & -0.10 & 0.21 & -0.08 & 0.24 & -0.11 & 0.06 \\
\hline $\begin{array}{l}\text { Most constricted } \\
\text { area (mm2) }\end{array}$ & -0.01 & 0.10 & 0.06 & 0.08 & -0.18 & 0.24 & 0.08 & 0.02 & -0.24 \\
\hline $\begin{array}{l}\text { Nasal Cavity } \\
\text { Volume (mm3) }\end{array}$ & 0.10 & -0.03 & 0.02 & -0.08 & 0.00 & -0.05 & 0.07 & 0.04 & 0.06 \\
\hline $\begin{array}{l}\text { Nasopharynx } \\
\text { Volume (mm3) }\end{array}$ & 0.20 & -0.25 & 0.16 & 0.12 & -0.08 & -0.17 & 0.16 & -0.01 & 0.02 \\
\hline $\begin{array}{l}\text { Oropharynx } \\
\text { Volume (mm3) }\end{array}$ & 0.25 & 0.10 & 0.27 & 0.06 & -0.17 & -0.13 & 0.29 & 0.12 & -0.27 \\
\hline $\begin{array}{l}\text { Soft palate area } \\
\text { (mm2) }\end{array}$ & -0.21 & 0.03 & -0.13 & -0.10 & -0.08 & 0.06 & -0.09 & -0.16 & -0.02 \\
\hline $\begin{array}{l}\text { Soft palate } \\
\text { length (mm) }\end{array}$ & -0.08 & 0.02 & -0.15 & -0.08 & -0.04 & -0.39 & -0.09 & -0.05 & -0.03 \\
\hline
\end{tabular}

Table VIII: Area of most constriction 


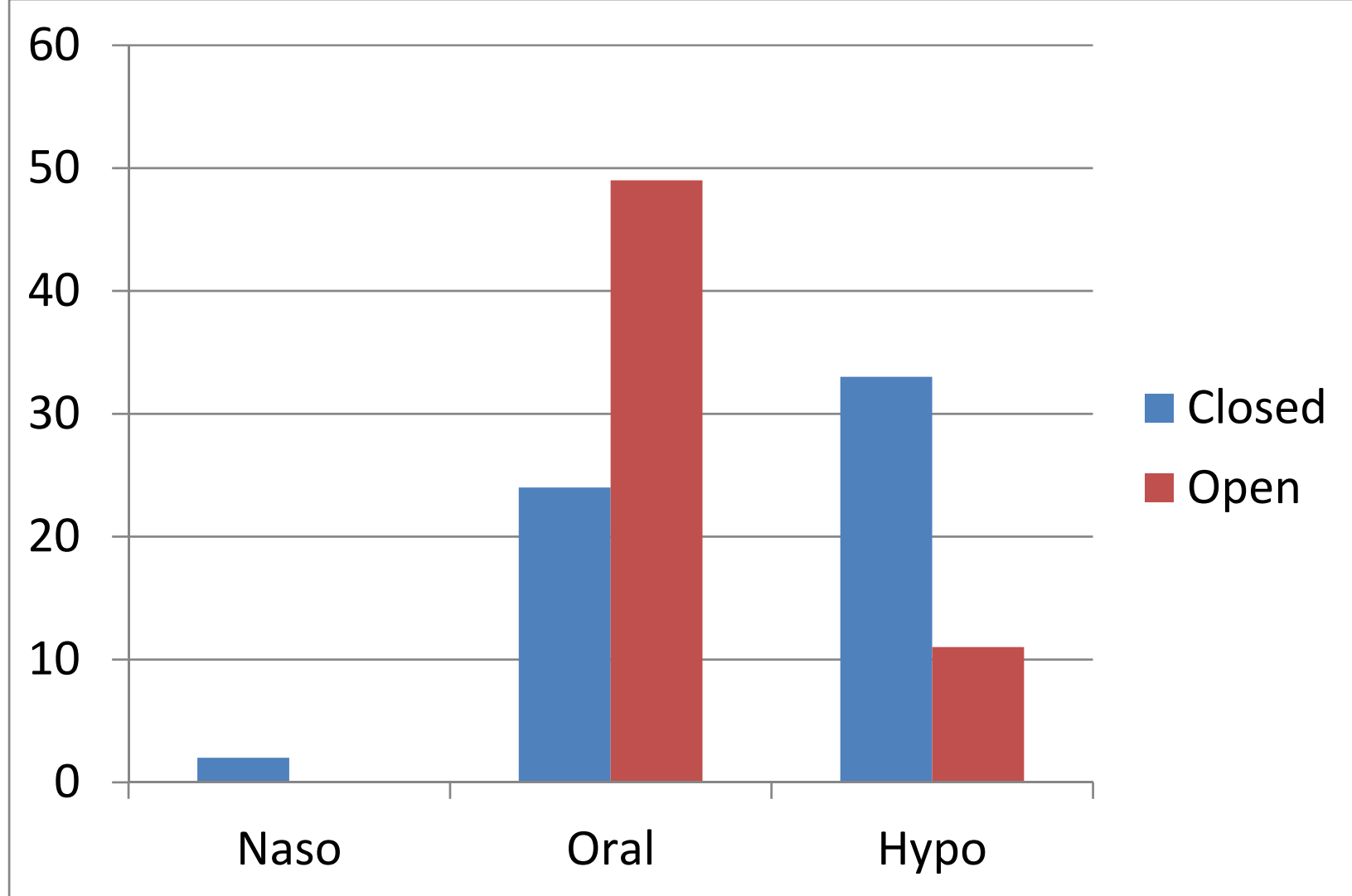


Figures

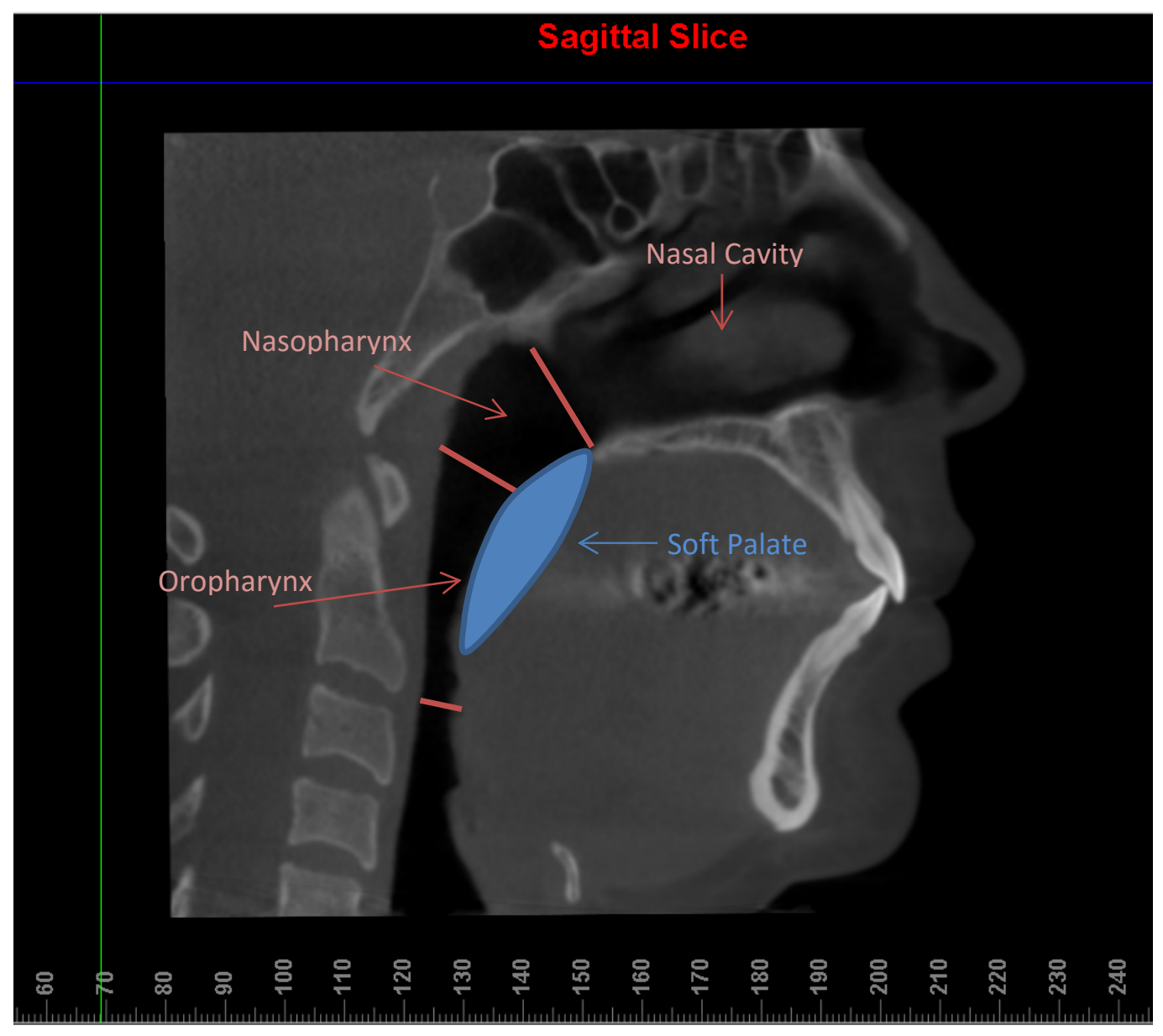

Fig 1. Airway anatomy 


\section{Sagittal (Draft)}

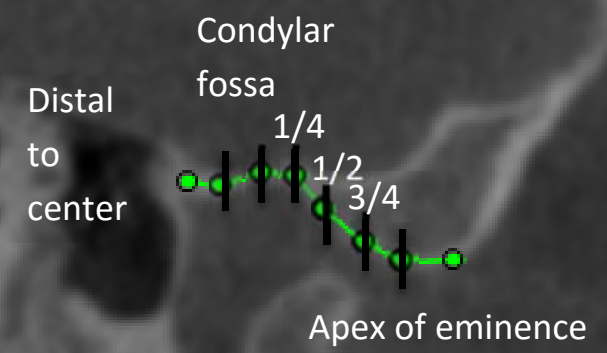

Fig 2. Condyle translation measured as distance traveled toward eminence. 


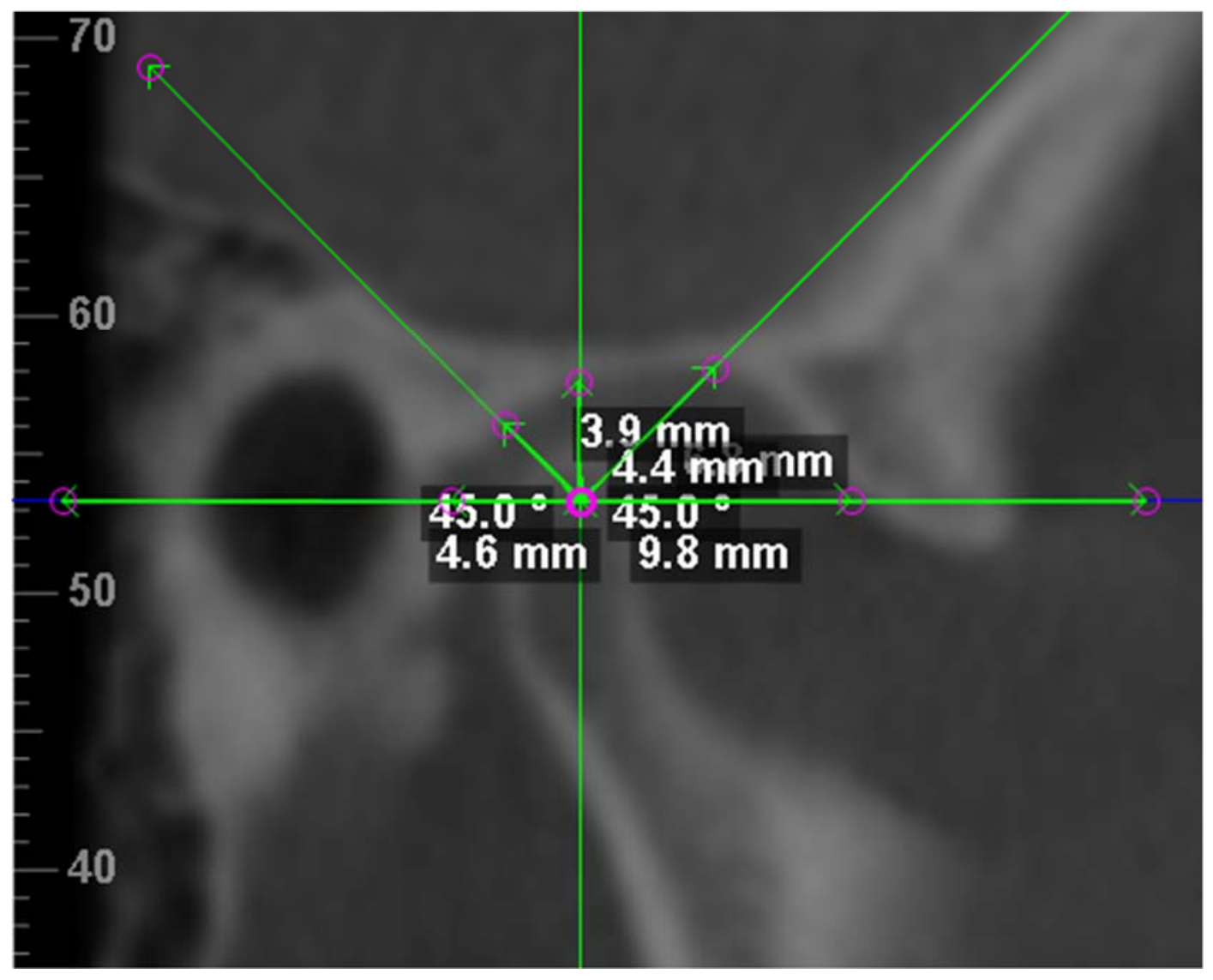

Fig 3. Linear condyle measurements closed jaw: anterior, antero-superior, superior, postero-superior, and posterior. 


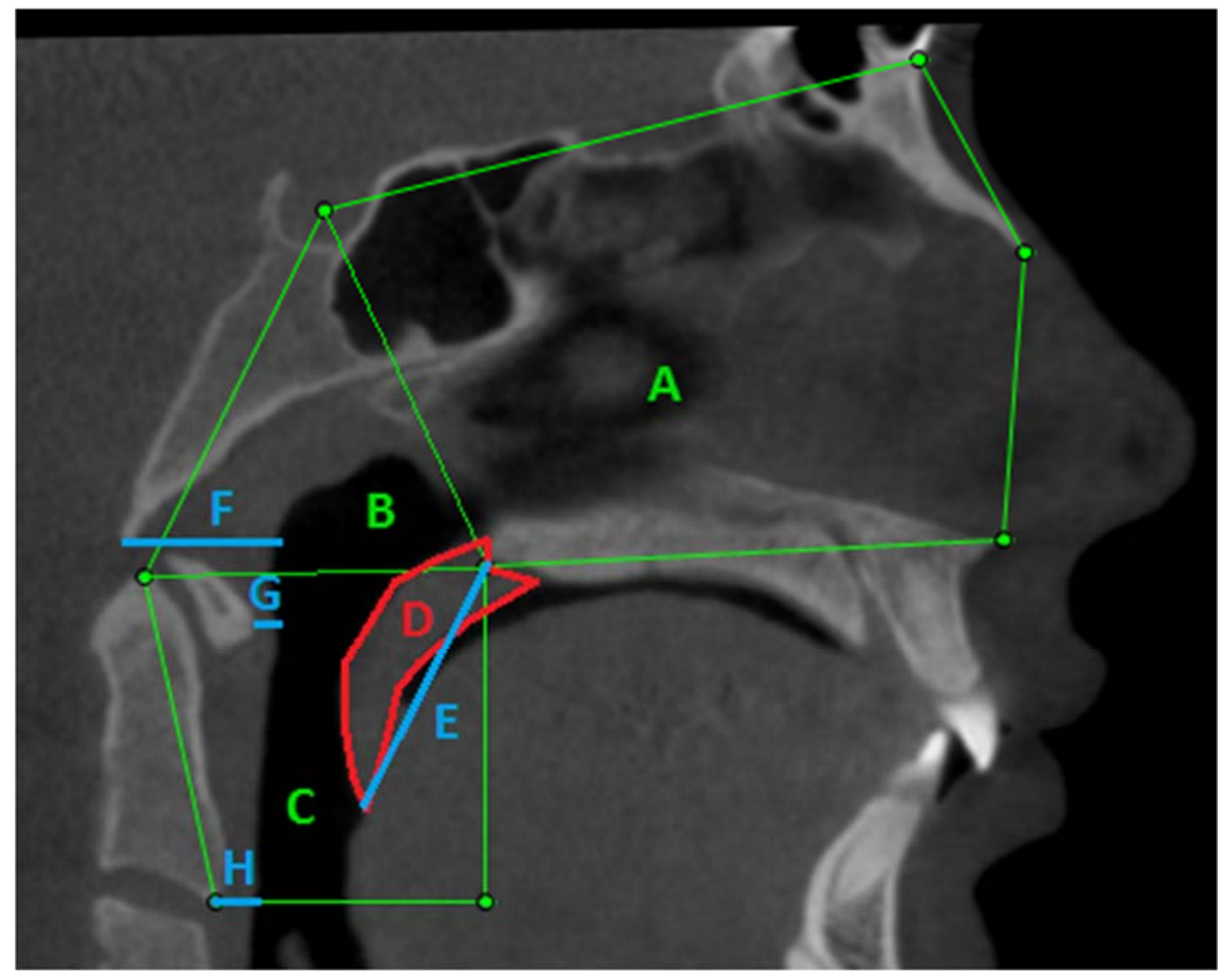

Fig 4. Measurements closed jaw: airway measurements in green (A: nasal cavity; B: nasopharynx; C: oropharynx). Area measurement in red (D: Soft palate). Linear measurements in blue (E: soft palate; $F$ : Ba-posterior airway wall; G: AA-posterior airway wall; H: CV2-posterior airway wall). 


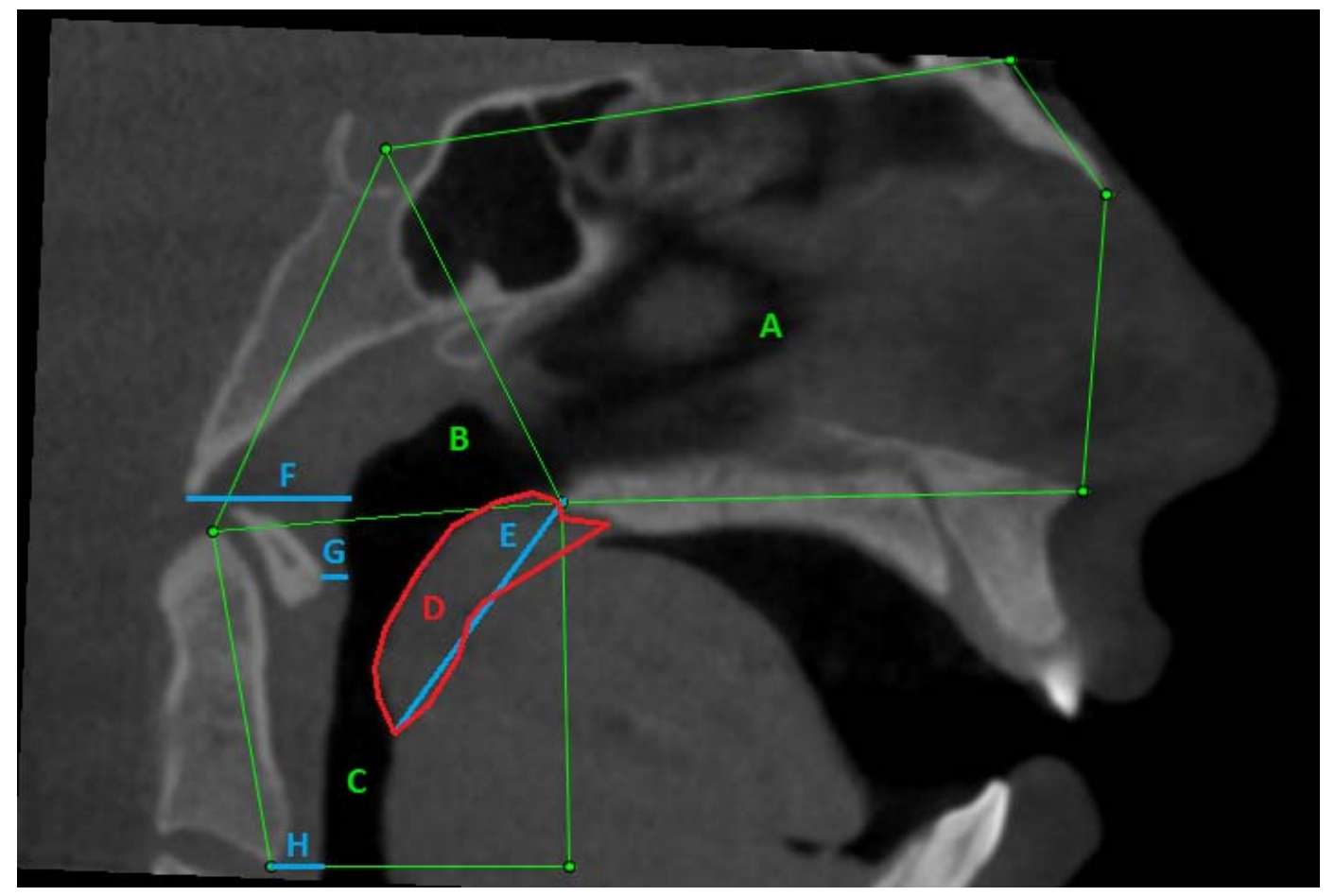

Fig 5. Measurements open jaw: airway measurements in green (A: nasal cavity; B: nasopharynx; C: oropharynx). Area measurement in red (D: Soft palate). Linear measurements in blue (E: soft palate; F: Ba-posterior airway wall; G: AA-posterior airway wall; H: CV2-posterior airway wall).

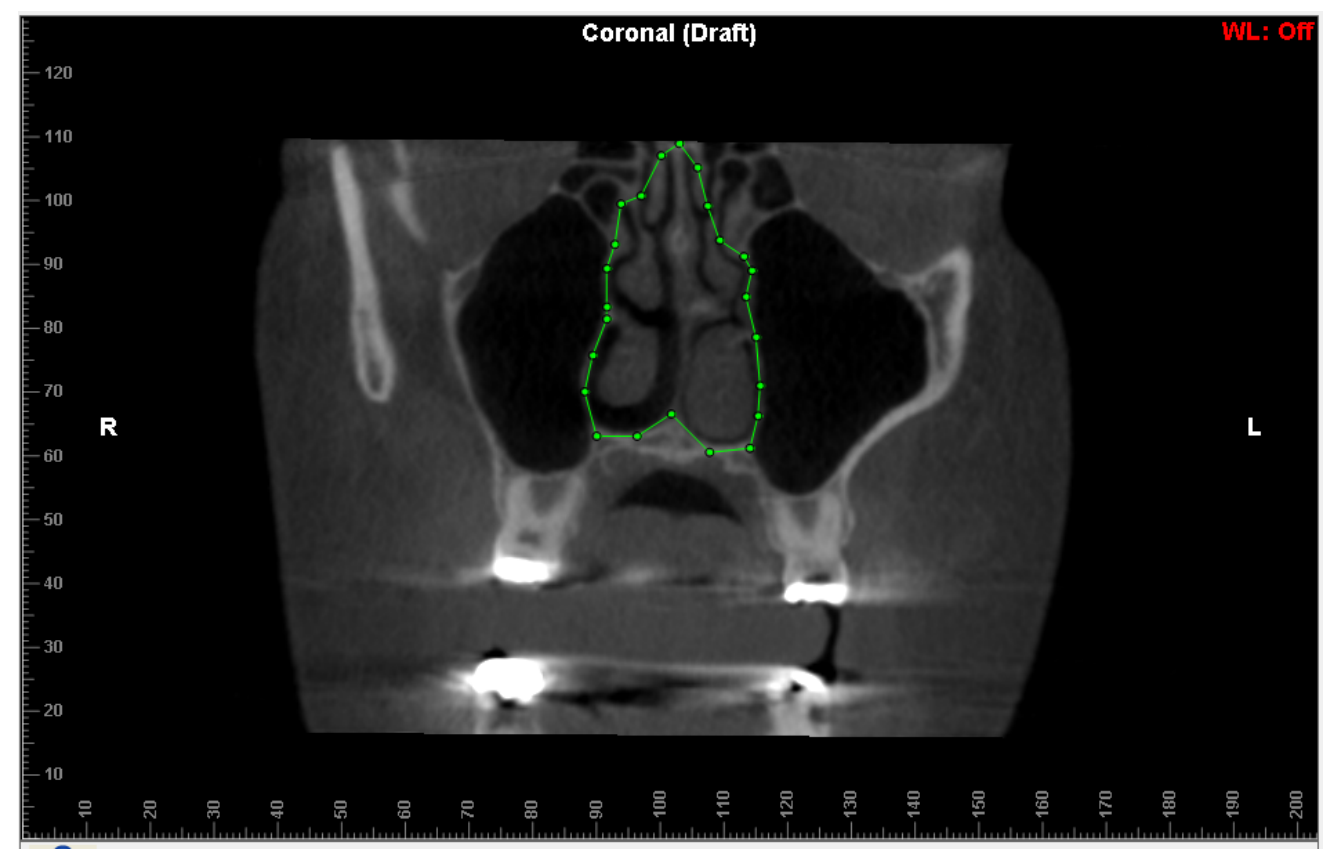

Fig 6. Nasal cavity coronal boundary. 


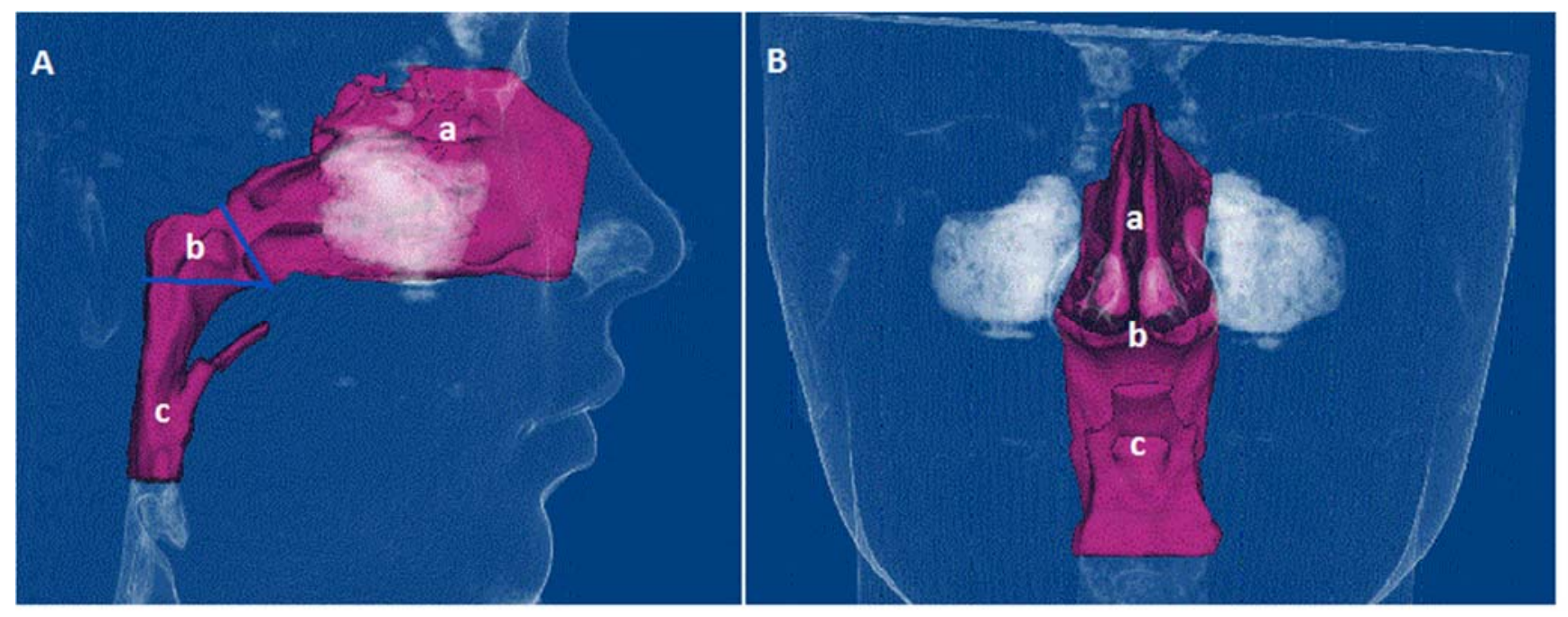

Fig 7. 3-dimensional airway boundaries rendering. A: Sagittal view of a. nasal cavity, b. nasopharynx, c. oropharynx. B: Frontal view of a. nasal cavity, b. nasopharynx, c. oropharynx. 